\title{
Characterization of Natural Antimicrobials in Food System
}

\author{
Jumana Mahmud, Ruhul A. Khan* \\ Institute of Radiation and Polymer Technology, Bangladesh Atomic Energy Commission, Dhaka, Bangladesh \\ Email: ^dr.ruhul_khan@yahoo.com
}

How to cite this paper: Mahmud, J. and Khan, R.A. (2018) Characterization of Natural Antimicrobials in Food System. Advances in Microbiology, 8, 894-916. https://doi.org/10.4236/aim.2018.811060

Received: October 13, 2018

Accepted: November 13, 2018

Published: November 16, 2018

Copyright $\odot 2018$ by authors and Scientific Research Publishing Inc. This work is licensed under the Creative Commons Attribution International License (CC BY 4.0).

http://creativecommons.org/licenses/by/4.0/

\section{(c) (i) Open Access}

\begin{abstract}
There has been a rising interest in using natural antimicrobial compounds in food industry due to current trend of giving value to natural and renewable resources. These antimicrobials provide new modalities to ensure microbial safety and extend the shelf-life of foodstuffs. Natural antimicrobials can be directly added into the food, but several efforts have been made to find alternative solutions to the aim of avoiding undesirable inactivation. Some different ways such as, dipping, spraying, and coating treatment of food are currently applied to product before packaging considered as valid options. The present paper aims to review the use of natural compounds to control microbiological and physicochemical shelf life of major food categories such as, meat, fish, dairy-based products, fruit and vegetables, and cereal-based products.
\end{abstract}

\section{Keywords}

Natural Antimicrobial Compounds, Food Preservation, Shelf-Life Extension

\section{Introduction}

Strong consumer demands safe, fresh-like (minimally processed), rich in nutritional value, and high-quality foods and also concerns about food safety due to increasing occurrence of new food-borne disease outbreaks caused by pathogenic microorganisms and fungi. This increases significant challenges, particularly as there is increasing unease regarding the use of chemical preservatives and artificial antimicrobials to inhibit growth of spoilage and pathogenic microorganisms. Many of these microorganisms can cause undesirable reactions that deteriorate flavor, odor, color, sensory, and textural properties of foods [1] [2] [3]. Some specific microorganisms, such as Listeria monocytogenes, Escherichia coli O157:H7, Salmonella spp., Staphylococcus aureus, Bacillus cereus, Campylobac- 
ter spp. and Clostridium perfringens, not only affect food quality but also constitute a hazard for human health, causing food-borne diseases. Food-borne diseases are a rising public-health problem worldwide. For example, it is expected that 31 pathogenic species are responsible for 9.4 million cases of food-borne diseases each year in the USA alone [4] [5]. To prevent growth of food-borne pathogens in foods, several preservation techniques, such as heat treatment, salting, acidification, and drying have been used in the food industry [6] [7].

A variety of synthetic antimicrobials, including several organic acids and salts (sodium benzoates and propionates, potassium sorbates, sorbic acid, sulphites, chlorides, nitrites, triclosan, nisin, natamycin, potassium lactate, ascorbic acid, citric acid, tartaric acid, etc.) have been approved by regulatory agencies and are used as food preservatives. However, the use of some of these represents a nutritional or health threat for the consumer [8] [9]. So, natural antimicrobials are receiving a good deal of attention to extend shelf life of food and prevent/control growth of micro-organisms, including pathogenic micro-organisms. Natural antimicrobials can be directly added into the product formulation, coated on its surface or incorporated into the packaging material to prevent growth of undesirable microorganisms in food. Such incorporation of active agents into food results in an instant but short-term reduction of bacterial populations, while the antimicrobial films can maintain their activity for a long period of time [10].

Major natural antimicrobial compounds are essential oils derived from plants (e.g., basil, thyme, oregano, cinnamon, clove, and rosemary), enzymes obtained from animal sources (e.g., lysozyme, lactoferrin), bacteriocins from microbial sources (nisin, natamycin) and organic acids (e.g., sorbic, propionic, citric acid) and naturally occurring polymers (chitosan) [11]. Spices and EOs are used as natural agents for extending the shelf life of foods in food industry. A variety of plant and spice-based antimicrobials is used for eliminating food-borne pathogens such as Salmonella, Listeria monocytogenes, Escherichia coli, Bacillus cereus, Staphylococcus aureus and increasing the overall quality of food products. More than 1340 plants with defined antimicrobial compounds, and above 30,000 components have been isolated from phenol group-containing plant-oil compounds, used in the food industry. Commercially based plant-origin antimicrobials are most commonly produced by SD (steam distillation) and HD (hydro distillation) methods, and alternative methods such as SFE (supercritical fluid extraction) from aromatic and volatile oily liquids from flowers, buds, seeds, leaves, twigs, bark, herbs, wood, fruits and roots of plants. The most common source of EOs are oregano, clove, cinnamon, citral, garlic, coriander, rosemary, parsley, lemongrass, sage and vanillin serve as antimicrobial, antioxidant compounds and widely used in smart or bioactive packaging material to prevent surface growth of microorganisms in foods [1] [2].

Spices and herbs are tremendous sources of antioxidants and have a long history of safe usage. Over 5000 years ago, the ancient Egyptians used a blend of spices such as cumin, cinnamon and onion and herbs in their food, for medicin- 
al purposes and for mummification [12]. Various Gram-positive and Gram-negative bacteria secreted bacteriocins are ribosomally synthesised antimicrobial peptides or complex proteins. Without showing toxicity, bacteriocins from many bacteria have been reported to be active against human and animal microbial pathogens, including methicillin-resistant Staphylococcus aureus (MRSA) and vancomycin-resistant Enterococci (VRE). Several bacteriocins have been recovered for their significant potential as food preservatives or as therapeutic or bio-controlling agents [13] [14]. In this regard, the application of natural antimicrobials is dramatically important as natural preservative strategies to protect and extend the shelf-life of food [15] [16].

Chitosan represent another group of natural antimicrobial compound that received considerable interest for commercial applications. It has been used in food, medical, agricultural, and chemical industry, mostly because of its high biodegradability and antimicrobial properties. It is produced from crab and shrimp shell wastes, with diverse deacetylation grades and molecular weights. It has been reported to possess a film-forming property for use as edible film or coating, to decline water vapor and oxygen transmission, reduce respiration rate and increase shelf-life of fruit [6].

\section{Natural Antimicrobials}

\subsection{Essential Oils}

Essential oils are natural, volatile and complex liquids known as volatile odoriferous oils characterized by an intense smell and flavor that varies depending on the type of constituents that form the oil. They are isolated from aromatic plants as secondary metabolites, especially by plants generally located in warm areas such as tropical and Mediterranean areas. EOs perform a major role in plants defense, working as antibacterial, antifungal and antiviral agents. They have originally been added to food in order to change or improve the flavor, their antimicrobial actions make them good candidates to replace chemical preservatives and suitable alternatives to antibiotics [17] [18].

Chemically the EOs consist of terpene compounds, alcohols, acids, esters, epoxides, aldehydes, ketones, amines and sulfides [19] [20]. Components contained in EOs can be divided into two groups are: terpenes (monoterpenes and sesquiterpenes) and terpenoids (monoterpenoids). At present, more than 3000 EOs are known, with 300 of them having a commercial interest in food, pharmaceutical, sanitary or cosmetic industries. Various terpene components of EOs (e.g. linalool, thymol, carvone, carvacrol, citral and limonene) from a total number of 30,000 described molecules have been accepted by the European Commission as flavorings for food products. These components have been acknowledged by the US Food and Drug Administration (FDA) as GRAS (Generally Recognized as Safe) ingredients, which allows their use in food products as safer additives [4] [21].

The main sources of well-known EOs are ginger, oregano, rosemary, sage, 
thyme, mint, and many other aromatic plants. EOs can be isolated by means of water distillation, water and steam distillation, or steam distillation alone. These are the most conventional and commonly used method of extraction. Another method, namely cohobation, can be used when the solubility of a certain essential oil in water is high, as in the case of geranium, rose, or lavender. Maceration and enfleurage processes are also used for obtaining EOs, as well more modern techniques such as extraction with solvents or supercritical fluids and ohmic assisted hydrodistilation. When the yield from distillation is poor maceration method can be used, while enfleurage and solvent extraction is suitable for costly, fragile, and thermally unstable materials [15] [22].

The foremost bioactive compounds are alcohols, aldehydes, phenylpropanoids, terpenes and ketones that have been found in EOs and are related to their antioxidant. Apart from the antioxidant activities, the incorporated EOs could provide antibacterial properties, including Staphylococcus aureus, Enterococcus faecalis, Escherichia coli, Clostridium perfringens, Clostridiumsporogenes in several meat products [15]. Usually terpenoids and phenylpropanoids are among the major components of common EOs in the food industry. EOs are used in a broad range of consumer goods such as confectionery food products, soft drinks, and distilled alcoholic beverages. As well as their extensive use as a flavoring material, they are used in the nutritional and agricultural fields for their reported antibacterial, antifungal, antiviral, nematicidal, insecticidal, and antioxidant. Due to this, their use as antioxidants and preservatives in food has been recommended, either incorporated into the food stuff packaging material or as plant and crop protectants [23] [24].

Isolation Method of Essential Oils: Extraction method is one of key factors that determine the quality of EO. Inappropriate extraction conditions can damage or alter the chemical property of the EOs [24] [25]. Thus, appropriate extraction method and extraction technique are important considerations in producing an EO with desirable characteristics. Therefore, new extraction techniques of EOs are recently proposed as alternatives to the traditional methods [22] [26] [27]. Essential oils can be extracted by several different methods are shown below:

\section{Conventional Extraction Methods:}

Steam Distillation: In this process, water is boiled, and plant sample is exposed to the resulting steam. The heat applied is the major cause of burst and break down of cell structure of plant material. As a consequence, the volatile aromatic compounds or EOs from plant material are released by steam and transported into a tube where the resulted vapor cool down to produce a mixture of distilled water and EO. Later, the EOs are separated from aqueous phase due to the differences in their specific gravity. Steam temperature, pressure and extraction duration are the most important considerations in the steam distillation process. In addition, steam distillation is a time-consuming process that sometimes involves a redistillation of the EO [28] [29]. Besides, one disadvantage of this conventional extraction method is the degradation of some volatile 
compounds as a result of long extraction times and relatively high temperatures [30].

Hydrodistillation: Hydrodistillation is one of the oldest and standard method of EO extraction technique [31]. In this process, EOs are extracted from the fragile parts of the plants through a solid-liquid extraction between plant material and hot water in a distillation container equipped with a Clevenger apparatus. The plant sample and water mixtures are boiled to get a vapor phase in the condenser section and collect the isolated EO in a receiver flask. This extraction method requires several disadvantages, such as long extraction times, which could promote hydrolysis of some heat sensitive components of the EOs and produce unwanted compounds [32]. Moreover, process parameters such as, process temperature and time, are difficult to control which may result in incomplete or prolonger extraction. So, researchers are looking for alternatives to this tedious extraction technique [32] [33] [34].

Hydrodiffusion: It is a one kind of steamdistillation, which is only different in the inlet way of steam intothe container of still. This method is suitable for use when the plant materialhas been dried and is not damaged at boiling temperature [35]. In this process, steam is applied from the top of plant material, while steam is entered from the bottom for steam distillation method. This method can also be operated under low pressure and reduces the steam temperature to below $100^{\circ} \mathrm{C}$. Hydrodiffusion method is better than steam distillation due to shorter processing time and a higher oil yield with less steam used [25].

Solvent Extraction: This process is used when plant materials are delicate or cannot bedistilled by other techniques. The purpose of solvent extraction is extracting the odoriferous lipophilic materials from the original plant by food grade solvents like methanol, ethanolor hexane [36]. It is important to select proper extraction solvents in this process, and the experts avoid solvents that can interfere with the extraction process or react with the extract. At first, plant samples are washed with the extraction solvent (breaking the material or centrifuging in a rotating drum) and the solvent is filtered and subjected to vacuum distillation to remove solid plant materials. The resulting mixture contains the aromatic and lipid-soluble compounds. After that, a second solvent (usually alcohol) is used to remove non-aromatic fractions. Lastly, another vacuum distillation is operated to eliminate the second solvent and obtain a pure mixture. In this case, the product is called "herbal extract" which has a diverse composition from that of EO [15].

Innovative Extraction Techniques: EOs are thermo-labile. So, high temperatures can alter their structures (hydrolyse, isomerization, oxidation) and inversely affect their antioxidant and antimicrobial properties during traditional extraction methods. Several alternative methods have been developed and proposed recently to solve these issues [29]. Besides, the combination of these innovative extraction techniques could improve the performance of the extraction process and increase the extraction yield [37]. 
Supercritical Fluid Extraction: This process occupies the supercritical fluids, such as carbondioxide, as an inert solvent to separate the volatile compounds from medicinal plants. The $\mathrm{CO}_{2}$ gas reaches a supercritical state under low pressure and temperature, becoming a liquid which can diffuse throughout plant material to extract aromatic compounds. The resulting extracts are considered as high quality, clean and pure, have a great similarity to the aroma of the original plant before extraction process [38]. In this extraction process, around $35^{\circ} \mathrm{C}$ temperature are used for thermally and sensitive compounds, maintaining the quality of the final product [39]. Though supercritical fluid extraction is expensive, it is very efficient due to its low viscosity and high diffusivity. The use of shorter extraction times (around 25 minutes) and the versatility of this method compared to conventional extraction ones, offers the possibility of selecting the characteristics of the resulting EO by modifying the temperature, pressure and extraction duration. In addition, this method can be considered as an environment-friendly extraction technique for the extraction of bioactive ingredients [40].

Microwave-Assisted Extraction: Microwave-assisted extraction is basically a combination of microwave heating and a conventional extraction method such as solvent extraction and hydrodistillation [41]. To facilitate the principles of "green" extraction methods, a new methodology as solvent-free microwave-assisted extraction was also developed [42]. In this process, the plant material is extracted without any organic solvent or water. This technique is considered as superior to traditional methods because it can reduce the extraction time and energy [43].

Ultrasound-Assisted Extraction: This technique releases the EOs from aromatic plants mostly through the cavitation phenomenon, which develops the penetration of the solvents in the plant material [44]. Cavitation occupies the formation, expansion, and growth of small liquid-free zones or bubbles which collapse strongly producing mechanical forces as well as local high temperatures and pressure at ambient conditions, therefore allowing the release and dissolution of intracellular materials such as EOs. This process can enhance the quality of the extract by minimizing thermal degradation of the $\mathrm{EO}$ components at a reduced temperature [45].

\subsection{Spices and Herbs}

Spices come from different parts of a plant except leaves whereas herbs come from leaves of a plant. Spices and herbs can be classified into a variety of groups based on flavor/taste, taxonomy or part of the plant where they came from. According to flavor, spices and herbs can be classified into 4 groups: hot spices (black and white peppers, cayenne pepper, mustard, chillies), mild flavor spices (paprika, coriander), aromatic spices (clove, cumin, dill fennel, nutmeg, mace, cinnamon) and aromatic herbs and vegetables (thyme, basil, bay leaf, marjoram, shallot, onion, garlic). Based on taxonomic classification, spices and herbs fall under the class Angiospermae or the flowering plants [12]. Spices and herbs are rich sources of phytochemicals and powerful antioxidants as they contain effec- 
tive compounds that have been shown to impart antioxidative effect in food. For more than 2000 years, spices and herbs have been used as flavor, color and aroma. Phytochemicals are a large group of bioactive compounds derived from plants which have capability to protect against diseases. This group contains flavonoids and other phenolic compounds, carotenoids, plant sterols, glucosinolates and other sulphur-containing compounds. More than 6000 flavonoids are identified. Phenolic compounds play a major role in the plant such as structural, defense, as attractants for pollinators and seed-dispersing animals. These substances help plants to protect themselves against UV light for their survival and for adaptation to their environment. Due to their phytochemicals, they have also been used for preservation of foods and beverages primarily. The spices and herbs have been used as antioxidants as many ways such as, whole or ground spice/herb, extracts, encapsulated or as emulsions [12] [46].

A large amount of spices have eastern origins; however, some of them have been introduced after invention of the New World spices such as chili peppers, sweet peppers, allspice, annatto, chocolate, epazote, sassafras, and vanilla, which have been used for food flavoring and medicinal purposes. In India, clove, cinnamon, mustard, garlic, ginger and mint are still applied as alternative health remedies. Plant extracts and spices also act against Gram-positive pathogens such as Listeria monocytogenes. They can also increase storage stability using active components including phenols, alcohols, aldehydes, ketones, ethers and hydrocarbons, especially in such spices as cinnamon, clove, garlic, mustard, and onion. In the 1880s, the first scientific studies were reported about preservation potential of spices, describing antimicrobial activity of cinnamon oil against spores of anthrax bacilli. Furthermore, clove was used as a preservative to cloak spoilage in meat, syrups, sauces and sweetmeats. In the 1910s, cinnamon and mustard were shown to be useful in preserving applesauce. Later some other spices, such as allspice, bay leaf, caraway, coriander, cumin, oregano, rosemary, sage and thyme, have been reported to have considerable bacteriostatic properties [1] [47].

\subsection{Bacteriocins}

Several microbes such as, Pediococcous spp., Leuconostoc spp., Lactobacillus spp., Streptococcus spp. etc. can produce key metabolites such as acids, alcohols, diacetals and various antibiotics such as inhibitory proteinaceous molecules commonly called bacteriocins [13]. Bacteriocins are abundant, have large diversity and a type of ribosomal synthesized antimicrobial peptides or proteins which can kill or inhibit other closely-related (narrow spectrum) or non-related (broad spectrum) microbiotas, but will not harm the bacteria themselves by specific immunity proteins. Bacteriocins were first discovered by Gratia in 1925. 99\% of all bacteria can produce at least one bacteriocin, mostly are not identified but in recent years, several bacteriocins such as, Lactobacillus spp., Enterococcus spp., Pediococcus spp., Leuconostoc spp., Lactococcus, Streptococcus and Carnobacterium are successively identified by scientists [47]. 
Due to the specific characteristics of huge diversity of structure and function, natural resource and being stable to heat; bacteriocins are considered to be one of the weapons against micro-organisms. They are commonly used in agriculture, veterinary medicine as a therapeutic, in food science to extend food preservation duration which reduce pathogen infection of animal diseases, pharmaceutical industry and medical society to treat cancer therapy [47] [48] [49]. Nowadays public is more aware of the importance of food safety, as many of the chemical additives used in food may elicit toxic concern; thus, it is beneficial to claim natural resources and health benefits of diets. However, a good number of commercially available preservatives and antibiotics are produced by chemical synthesis and long-term consumption of such products may have an adverse impact on the human body as they decrease the number of bacteria in the gut. Besides, the use of antibiotics or residues in food is considered as illegal. So, bacteriocins may be used as a potential drug candidate for replacing antibiotics to treat multiple drugs resistance pathogens in the future. Bacteriocins are considered as natural food additives because they are produced by bacteria present in many types of foods since ancient times, such as cheeses, yogurts, and Portuguese fermented meat. Instead of using antibiotics and chemical preservatives, "Generally Recognized As Safe"(GRAS) bacteriocins, such as nisin is produced by Lactococcus lactis and was the first antibacterial peptide found in LAB (Lactic acid bacteria), used as a food preservative in vegetables, dairy, cheese, meats, and other food products, as they inhibit microbial contamination during the production process [50].

Production and Extraction of Bacteriocins: The conventional determination of the antagonism of a bacteriocin-producing strain against a sensitive strain, indicated as "producer" and "indicator", respectively, can be performed in various ways. Usually, most common methods are agar-spot deferred test and agar-well diffusion assay [51]. In the first method, producer strains are allowed to grow overnight on the surface of the optimal agar medium. Then indicator strain is inoculated into the optimal soft agar medium and poured on the plate where growth of the producers occurred. After incubation, bacteriocin inhibition is indicated by the presence of a detectable clearing zone around the colony of the producer strain. In the second method, the agar base medium is overlaid with soft agar medium containing the indicator strain, as above. After that, wells are cut into the agar and the cell-free supernatant of the bacteriocin producer strains is placed into each well. The inhibitory effect of lactic acid and/or $\mathrm{H}_{2} \mathrm{O}_{2}$ is reduced by the adjustment of supernatants to neutral $\mathrm{pH}$ and treatment with catalase, respectively. Agar-based antagonistic assays of bacteriocin detection may be replaced by quicker tools. A rapid method was developed to examine culture supernatants for the presence of some bacteriocins, such as brochocins A and $\mathrm{B}$, enterocins $\mathrm{A}$ and $\mathrm{B}$, nisin and pediocin, by means of the matrix assisted laser desorption/ionization time-of-flight mass spectrometry [14]. In addition, PCR (Polymerase Chain Reaction) methods have also been used to detect genes coding for bacteriocins in pure cultures [52] and fermentation broth [53]. 


\section{Mechanisms of Action}

A wide range of microorganisms have been used to screen the antimicrobial effects of EOs over the years, but their modes of action are still not fully understood. EOs contain numerous components and their antimicrobial activity cannot be confirmed based only on the action of one compound. Thus, several mechanisms have been proposed to elucidate the actions of the chemical compounds contained in the EOs [19]. Several researchers have proposed that plant substances affect microbial cells by various antimicrobial mechanisms, including attacking the phospholipid bilayer of the cell membrane, disrupting enzyme structures, compromising the genetic material of bacteria, and forming fatty acid hydroperoxidase caused by oxygenation of unsaturated fatty acids [1]. EOs, as natural antioxidants, provide protection against oxidation. Some factors can affect lipid oxidation include the presence of oxygen and transition metal ions, moisture, heat and light. EOs have several mechanisms of action to slow down the oxidation reactions such as prohibition of chain initiation and continued hydrogen abstraction, free radical scavengers, termination of peroxides, quenchers of singlet oxygen formation and binding of transition metal ion catalysts [15]. With those functions, EOs can serve as the potential natural antioxidants to prevent lipid oxidation of fats and oils in foods. The majority of the antioxidants come from spices and herbs act by reacting with free radicals formed during the initiation stage of autoxidation and others form complexes with metal ions. The principal components of several EOs are phenolic compounds and can comprise up to $85 \%$ of the total composition of some EOs. Most well-known phenolic compounds are carvacrol, eugenol, and thymol known as primary antioxidants or chain-breaking antioxidants, and effective free radical scavengers [21]. Those phenolic components of EOs also elicits an antimicrobial reaction by disrupting the cell membrane that results in the inhibition of the functional properties of the cell, and eventually cause leakage of the internal contents of the cell against food-borne pathogens. The mode of action of phenolic compounds may relate to alter bacterial cell permeability, damage cytoplasmic membranes, interfere with cellular energy (ATP) generation system, and interrupt the proton motive force. Moreover, by damaging the cytoplasmic membrane cell death can occur [19].

Bacteriocins have been seen to exert their mode of action by different mechanisms against Gram-positive and Gram-negative bacteria through cell wall disruption or inhibition of protein or nucleic acid synthesis. Bacteriocins can bind to cell wall components, including lipid or surface molecular binding sites, using specific or non-specific receptor binding, that results in pore formation or direct cell lysis and eventually cell death occur via dissipation of the proton motive force of the bacterial system. Yet, nisin attacks the cytoplasmic membrane of Gram-negative bacteria when combined with ethylene diamine tetra-acetic acid (EDTA) more efficiently because of the chelating effect of EDTA with cell wall components. In addition, mersacidin also kills Gram-positive bacteria by cell wall inhibition. Another example includes, bacteriocin colicin and its killing 
mechanism towards Gram-negative bacteria has also been discovered to be membrane pore formation [13].

\section{Food Applications of Natural Antimicrobials}

In-food experiments depend on a number of additional factors, which have not been tested in similar in vitro studies. Natural antimicrobial compounds can be used as an alternative preservative and pathogen-control method in food materials. Application of both extracts and EOs of plant-based antimicrobials could be a potential alternative to synthetic preservatives. Usually, the antimicrobial activities of efficient EOs in decreasing order are: oregano $>$ clove $>$ coriander $>$ cinnamon $>$ thyme $>$ mint $>$ rosemary $>$ mustard $>$ cilantro/sage. Though, mint showed less antimicrobial effect compared to mustard was reported in another study. There are dissimilarities between in vitro and in-food trials of plant-origin antimicrobials, mostly because only tiny percentages of EOs are endurable in food materials. Even though some positive reports towards application of plant-origin natural antimicrobials, two most important issues are faced regarding application of plant-origin antimicrobials in food, one is odors created mostly by the high concentrations and another is the costs of these materials [1] [54]. So, safety issue is very important for natural antimicrobials for the use in food products. An enormous number of very effective natural antimicrobials exists in nature. However, not all natural antimicrobials are suitable for food applications because of safety issue. Toxicological testing of natural antimicrobials is mandatory for industries before using in food [55].

\subsection{Meat-Based Products}

Spoilage of meat products results in deterioration of texture and change in flavor and color. Natural antibacterial compounds, such as extracts of spices and herbs, EOs, organic acids, salts, and bacteriocins used to improve the shelf life of meat are reported in the literature [6]. The combination of natural antimicrobials, such as lemon and thymol with modified atmosphere packaging (MAP) are used to improve the shelf-life of reduced pork back-fat content sausages. It has been shown that the application of thymol and thymol-MAP limited the development of Pseudomonas spp., responsible for sausages' unacceptability. The combined use of winter savory (Satureja montana) EOs with other preservation methods such as reduced temperature, high pressure, pulsed light, pulsed electric and magnetic fields, irradiation, or MAP can be utilized to control growth of food-borne bacteria and improve quality of minced pork. Further, winter savory EOs were used successfully to raise radio sensitivity in ground beef [56]. Combinations of bay essential oil and MAP without oxygen $\left(20 \% \mathrm{CO}_{2}-80 \% \mathrm{~N}_{2}\right)$ showed to control the growth of L. monocytogenes and E. coli and also to extend the shelf-life of naturally contaminated ground chicken meat. Besides, the addition of EOs of marjoram and rosemary to beef patties prepared with mechanically deboned poultry meat at a concentration of $200 \mathrm{mg} / \mathrm{kg}$ reduced lipid oxida- 
tion and improved the sensory characteristics. By extracting aqueous form of rosemary, sage and thyme rancidity of heat-treated turkey-meat products was inhibited. The addition of orange dietary fiber (1\%), rosemary essential oil $(0.02 \%)$ and thyme essential oil $(0.02 \%)$, combined with specific storage conditions in mortadella, a Bologna-type sausage helps to reduce microbial growth and to preserve the oxidative constancy. Antioxidant and antibacterial effects of rosemary, orange, and lemon extracts was also examined in cooked Swedish-style meat-balls. Results revealed that significant advantages were obtained using rosemary and citrus extracts in rancidity-susceptible meat products; but, only rosemary slightly reduced lactic acid bacteria [56]. One study showed that, individual extracts of clove, rosemary, cassia bark and liquorice showed strong antimicrobial activity; but the mixture of rosemary and liquorice extracts was the best inhibitor against all four types of microbes (L. monocytogenes, Escherichia coli, Pseudomonas fluorescens and Lactobacillus sake) in MAP fresh pork and vacuum-packaged ham slices stored at $4^{\circ} \mathrm{C}$ [57] [58].

In food technology, bacteriocins such as, nisin used as a commercial food preservative against microbial contamination, which is marketed as Nisaplin ${ }^{\bullet}$ and approved for consumption as a preservative in many foods by the U.S. Food and Drug Administration (USFDA), and licensed as a food additive in over 45 countries. One more commercially available bacteriocin is pediocin PA-1 inhibits the growth of Listeria monocytogenes in meat products, which is marketed as Alta 2341 [47]. The combined use of lactoferrin and nisin on naturally contaminated Turkish-style meat-balls was proposed. The combined antimicrobial activity of lysozyme, nisin, and EDTA against L. monocytogenes and meat-borne spoilage bacteria was observed in ostrich patties packaged in air and vacuum. Specifically, the antimicrobial activity was effective for controlling growth of lactic acid bacteria though it was not effective against Gram-negative bacteria [59].

As regards chitosan, $0.5 \%$ and $1 \%$ added individually or in combination with nitrites $(150 \mathrm{ppm})$ as ingredients was examined to protect fresh pork sausages from microbial spoilage and its application as active coating was also established. The antimicrobial effect of commercial herbs, spices and EOs (fresh and dried garlic, onion, thyme, marjoram, and oregano) are compared in minced pork and the result revealed that fresh spices showed weak or no inhibition on viable cells of minced pork while essential oils showed a little effect. Best shelf life values were attained for pork meat added with garlic and marjoram oil. To improve the shelf life of meat-based products, dipping of thyme and oregano oil in concentrations of $0.1 \%$ and $0.3 \%$ were approved [60].

\subsection{Fish-Based Products}

Thyme (1\%) and laurel essential oil (1\%) was used to extend the shelf life of bluefish by about 3 - 4 days [61]. It was also observed that the quality of hot smoked rainbow trout packaged under vacuum which is treated with thymol and garlic 
oil (1\%) was improved. The addition of MAP and thyme essential oil (0.1\%) resulted in a shelf life extension of fresh Mediterranean swordfish fillets. In particular, individual thyme essential oil can extend product shelf life (13 days) if compared to the control (8 days), while its combination to MAP conditions further prolonged product shelf life (about 20.5 days). Some fish have high fat content, like meat products, reduces the antibacterial effect of EOs against various micro-organisms; still, some of the EOs had positive effects even in the high-fat-content fishes. For instance, oregano oil is more effective against the spoilage bacteria Photobacterium phosphoreum on cod fillets than on salmon, which is a fatty fish. In addition, oregano oil is more effective than mint oil in/on fish, even in fatty-fish dishes. It was found that $0.8 \%$ oregano oil extended shelf life of sea bream fillet by more than 17 days [62]. Almost same results were also reported on rainbow trout where the similar combined strategies decreased the cell load of main spoilage microorganisms. Shelf life of carp fillets was extended four-fold by the addition of carvacrol + thymol with some other additives, compare to sterile $0.2 \%$ agar solution as a control. The possibility to extend the microbial acceptability limit of fresh fish burgers by using a mixture of three natural compounds such as, thymol, grape-fruit seed extract and lemon extract can prolonged the sensory quality without compromising the flavor of fish. Those three compounds were used in combination with MAP to demonstrate that MAP further enhanced the effects of the natural active compounds. Moreover, the antimicrobial and antioxidant activity of purple rice bran extract against catfish patties was demonstrated in a study [63].

EOs of Aloysia sellowii were successfully screened in brine shrimp against a variety of Gram-positive and negative microorganisms and two yeasts, but after coating with an edible solution containing $0.5 \%$ eugenol $+0.5 \%$ linalool showed even better results in tuna slices compared to controls [64]. Coating with EOs was also proposed in literature as suitable technique to improve quality of fish products. It was reported that the use of a coating with chitosan and cinnamon essential oil improved trout fillet shelf-life (16 days vs. 10 days of the control) and also enhanced texture, odor, and color. Similar results were also obtained for trout fresh fillets coated with gelatin and cinnamon oil (1\%, 1.5\%, and $2 \%)$. Experimental data showed that the active coating system can be suitable for preserving the fillets and sustain quality to an acceptable level [65]. On the other hand, individual use of lactic acid and in combination with nisin for reducing microorganisms on chilled shrimp was evaluated. Best results were obtained when treated with the mixture of lactic acid and nisin against Pseudomonas spp. [66].

\subsection{Vegetables and Fruits}

Fresh-cut fruit and vegetables are broadly studied due to the difficulties in preserving their fresh-like quality during prolonged periods and the aim of fresh-cut products is to deliver convenience and high quality. Considering the demands of consumers about the use of synthetic chemicals, natural compounds 
have been suggested as a valid preservation technique. Some different ways of applications of active agents to fresh-cut fruit and vegetables are dipping, impregnation, coating, and spraying but among them, the most recent results deal with coating systems [16].

Alginate-based coating enriched with EOs incorporated into an fresh-cut Fuji apples showed more than 4-log reduction in the population of E. coli O157:H7 and extended the microbiological shelf life by more than 30 days. Lemongrass and cinnamon EOs $(0.7 \%)$, citral $(0.5 \%)$, and cinnamaldehyde $(0.5 \%)$ were the most effective antimicrobials. EOs of cinnamon, clove, and lemongrass and their dynamic compounds like cinnamaldehyde, eugenol, and citral have also shown promising antimicrobial and quality effects on fresh-cut melon. Combination of malic acid with various stabilizing compounds was used for fresh-cut apples. The combined effect of chemical dip and/or edible coating and/or controlled atmosphere (CA) on quality of fresh-cut banana was investigated [67]. For this reason, banana slices were dipped into a solution containing $1 \%(\mathrm{w} / \mathrm{v})$ calcium chloride, $0.75 \%(\mathrm{w} / \mathrm{v})$ cysteine, $0.75 \%(\mathrm{w} / \mathrm{v})$ ascorbic acid, and/or combined with a carrageenan coating and/or combined with $\mathrm{CA}\left(3 \% \mathrm{O}_{2}+10 \% \mathrm{CO}_{2}\right)$. The advantages of CA treatment+ chemical dip stopped product weight loss and increased polyphenol oxidase activity; regarding microbiological quality and also prevented microbial growth after 5 days of storage at $5^{\circ} \mathrm{C}$. The antimicrobial activity of propionic, malic, acetic, lactic and citric acid on whole red organic apples and lettuce against E. coli O157:H7, Salmonella Typhimurium, and L. monocytogenes were also demonstrated. EOs of pure citral and citron were added in the syrup of industrial ready-to-eat fruit salads stored at $9^{\circ} \mathrm{C}$. The application of natural volatile compounds such as methyl jasmonate, ethanol, tea tree oil and garlic oil were applied on fresh-cut tomato stored at $5^{\circ} \mathrm{C}$ for 15 days. However, ethanol combined with methyl jasmonate was more effective in suppressing microbial proliferation rather than each single compound. Besides, this combination conserved firmness and color better than the other antimicrobial preservatives [68].

Encapsulation of garlic oil in $\beta$-cyclodextrin and tested on microbial growth and sensory quality of fresh-cut tomato. Coating of sodium alginate with grape-fruit seed extract is used as antimicrobial compound to prolong the shelf-life of minimally processed kiwifruits. Such combinations delayed microbial growth, whereas the sole dipping treatment was ineffective. Furthermore, the combined use of modified atmosphere packaging (MAP) and coating treatments prolonged the shelf-life up to 13 days. Application of a combined effect of 40 ppm cinnamaldehyde and $80 \mathrm{ppm}$ eugenol or by itself preserved apple juice for 7 days and also tested for control the germination of alicyclobacillus spores [69].

Juices are very vulnerable to yeasts such as, Pichia anomala, Saccharomyces cerevisiae, and Schizosaccharomyces pombe caused the most diffuse problems. Generally, traditional processes, like heat treatment (pasteurization), aseptic packaging or use of weak acids prohibit yeast spoilage. As substitute to these conventional artificial preservatives, the use of natural compounds was proposed 
[70]. For example, sage, clary, juniper, lemon, and majoram EOs were used to preserve apple juice, as being efficient in in-vitro test. The effects of these EOs against yeast were good in the acidic $\mathrm{pH}$ range optimal for yeasts growth. In addition, synergism or additive effects were documented by combining the different active compounds. The most interesting result was experiments with lemon essential oil given to apple juices showed that the "open" storage time at ambient temperature could be prolonged and a novel, refreshing taste could be achieved [71].

The lactic acid bacteria (LAB) such as, Enterococci can be used as starter cultures or co-cultures for inhibiting microbial contamination. This bacteriocinogenic LAB strains reviewed as a co-culture, protective, or starter cultures in fermented and non-fermented vegetables, such as olives, sour-dough, miso, sauerkrauts, refrigerated pickles, and mungbean sprouts. In addition, they introduced nisin as food additives, which are used in mashed potatoes, kimchi and fresh-cut products. Furthermore, EnterocinAS-48 is used in fruit and vegetable juices, cider and canned vegetables for contamination inhibition [52].

\subsection{Cereal-Based Products}

It was reported that bread coated with chitosan improved bread quality during storage at room temperature by reducing microbial growth and retarding oxidation. Different applications of citrus peel EOs in bread was also reported and results showed that the oils influenced sensory characteristics and delayed microbial growth. An active packaging with cinnamon essential oil combined with MAP was examined in gluten-free sliced bread to increase the shelf-life and results pointed out that the active packaging is better than MAP because it inhibited microbial growth while maintaining the sensory properties of the gluten-free bread. Different natural antimicrobial compounds such as thymol, lemon extract, chitosan, and grape fruit seed extract at different concentrations (2000 mg/kg and $4000 \mathrm{mg} / \mathrm{kg}$ ) used to improve the microbiological stability of refrigerated amaranth-based fresh pasta. Results showed that chitosan were the most successful among the other compounds in slowing down the spoilage, while lemon extract was the less effective. Later, the antimicrobial activity of chitosan combined with different MAP was tested and found that among the tested MAP conditions the combination of $30: 70 \mathrm{~N}_{2}: \mathrm{CO}_{2}$ extended the shelf-life beyond two months [72].

The antibacterial activity of ethanol and water extracts of six types of leaves was tested against the major spoilage bacterial groups to improve the shelf-life of yellow alkaline noodle. Results revealed that ethanol extracts of aromatic leaf such as, Murraya koenigii L., superior than the other extracts. Another study showed that EOs from basil, oregano and thyme exhibit bactericidal activities against Bacillus cereus in rice-based foods. Moreover, different natural compounds such as, anise, black cumin, rosemary and sage showed antioxidant and antimicrobial activity to some bakery products. Initial results showed that all tested essential oils and phenolic compounds were sensitive to both 
Gram-positive and Gram-negative bacteria [71] [72] [73].

\subsection{Dairy Products}

Fresh dairy products are ready-to-eat foods easily contaminated by unwanted microorganisms and fungus. A few are spoilage microorganisms which may produce unwanted visual appearance and reduce the commercial value of cheese, other ones are pathogens that affect product safety. Recently the efficacy of natural compounds, alone or in combination with other preservation methods such as, spraying, immersing, or dusting have recorded when directly applied to milk or to cheese. Those compounds may also be spread onto the packaging materials that come in contact with the cheese or incorporated into the plastic films used for packaging. It has been revealed that extract of mango seed kernel could reduce total bacterial count, inhibit coliform growth, exert significant antimicrobial activity against an E. coli strain and extend the shelf-life of pasteurized cow milk. The combination of lysozyme and EDTA on microbiological shelf life of mozzarella cheese was studied. Results showed that mozzarella packaged in a brine that contained lysozyme $\left(0.25 \mathrm{mg} \cdot \mathrm{mL}^{-1}\right)$ and different amounts of $\operatorname{EDTA}\left(10,20\right.$, and $\left.50 \mathrm{mmol} \cdot \mathrm{L}^{-1}\right)$, and stored at $4^{\circ} \mathrm{C} \pm 11^{\circ} \mathrm{C}$ for 8 days. Such packaging system considerably inhibited growth of coliforms and Pseudomonadaceae, without affecting the typical lactic acid bacteria. Besides, effects of lysozyme and EDTA in burrata cheese packaged under MAP $\left(95: 5 \mathrm{CO}_{2}: \mathrm{N}_{2}\right)$ was evaluated. Therefore, these compounds were valid to extend cheese shelf-life, especially at high lysozyme concentrations [74].

The application of bacteriocins in soy milk and zucchini purée such as, Enterocin CCM4231 and EJ97 are used for suppression of contamination, respectively. Edible coatings made of galactomannans in combination with nisin were tested against L. monocytogenes in Ricotta cheese. This combination helps in retarding the growth of $L$. monocytogenes and also in the maintenance of water content, thus reducing cheese weight loss. Moreover, nisin was also incorporated into sodium caseinate-based films to be used in mini red Babybel cheese. It is reported [75] that natamycin was incorporated into wheat gluten and methyl cellulose biopolymers and tested against Aspergillus niger and Penicillium roquefortii spread on surface of fresh kashar cheese. Natamycin was also used in combination with edible coatings made of chitosan in one study. The efficacy of nisin, natamycin and their combination into a cellulose polymer matrix were studied on sliced mozzarella cheese and combined effects showed best results. Nisin was found to be effective on traditional Minas Serro cheese by reducing 1.2 and $2.0 \log$ cycles in Staphylococcus aureus count was observed from the $7^{\text {th }}$ day of ripening for cheese containing $100 \mathrm{IU} \cdot \mathrm{mL}^{-1}$ and $500 \mathrm{IU} \cdot \mathrm{mL}^{-1}$ of nisin, respectively, compared with control sample [52] [76] [77]

As regards the application of EOs, thyme $(0.2 \mathrm{ppm})$, marjoram $(0.5 \mathrm{ppm})$ and sage $(1 \mathrm{ppm})$ were tested on concentrated yoghurt. Results showed that better concentration of each EO was $0.2 \mathrm{ppm}$ that allowed obtaining a shelf-life up to 21 days. In addition, the anise volatile oil and its oleoresin added to yogurt at 
various concentrations $\left(0.1-1.0 \mathrm{~g} \cdot \mathrm{L}^{-1}\right)$ were effective in controlling spoilage microorganisms, stored up to 20 days at $4^{\circ} \mathrm{C} \pm 1^{\circ} \mathrm{C}$. In another study, total eleven EOs were evaluated in vitro testfor their antibacterial properties against Vancomycin-resistant Enterococci and E. coli O157:H7. Among them, most active essential oils were thyme oil, eucalyptus, juniper, and clove oils and their effects were further evaluated against the same microbial groups experimentally added in Feta soft cheese and stored at $7^{\circ} \mathrm{C}$ for 14 days. Besides, the addition of $0.5 \%$ and $1 \%$ thyme oil caused a significant reduction in microbial growth. Oregano and thyme ( 0.1 or 0.2 and $0.1 \mathrm{ml} / 100 \mathrm{~g}$ ) combined with MAP on Feta cheese against E. coli $\mathrm{O} 157: \mathrm{H7}$ and L. monocytogenes were also tested. Moreover, the addition of $75 \%$ eucalyptus oil and $25 \%$ lemon grass exerted a positive impact on the nutritional, sensory, and microbial values of West African soft cheese [78] [79].

\subsection{Animal Feed}

The use of thymol compound shows effects on the microbial community in animal feed. EOs showed partial effects on nutrient utilization in studies of alfalfa silage and corn silage as the sole forage source in ruminants. The efficacy of cinnamon leaf oil on total volatile fatty acid (VFA) concentration has been studied. So, it was illustrated that it reduces propionate-producing bacteria and might have an adverse effect on metabolism and productivity of ruminants [1] [80].

\section{Conclusions}

Consumers demand safe food products which contain natural ingredients due to concerns over adverse health effects of artificial or synthetic raw materials. These synthetic additives are used mainly to reduce pathogenic and spoilage bacteria to prolong shelf-life. Some of these antimicrobial additives may alter the nutritional properties of a given food; for example, sulphites can destroy vitamin B1, or the addition of nitrates to meat, which render their microbial conversion to nitrites and later formation of the carcinogenic nitrosamines. These types of scientific data, together with an increasing consumer demand compels the search of food authorities and researchers for natural preservation techniques to improve microbial quality and safety without causing nutritional and organoleptic losses. The various experimental applications of EOs, bacteriocins, enzymes, chitosan, and organic acids to various fresh consumable foods show that they are well suited to be utilized as preservatives in foods and could be often valid alternatives to synthetic food additives [6]. Lipid oxidation has a range of harmful effects on foods such as color fading, browning or color degradation and development of rancid flavor which renders the food unacceptable and also diminishes the nutritional value of foods. For this reason, spices and herbs have been used for thousands of years for flavor, aroma, as coloring in foods, and as preservatives and also effective in inhibiting lipid oxidation or slowing down the onset of rancidity in foods [12]. 
Application of natural antimicrobials such as, EOs of cinnamon, clove, lemon grass and their respective active compounds (cinnamaldehyde, eugenol and citral, respectively) has been recently outlined by regulatory agencies in the US, based on Code of Federal Regulation 21 CFR part 182.20. These EOs are generally recognized as safe (GRAS). Despite their great potential, their intense aroma and toxicity problems can limit their use in food preservation. When these oils are used, changes in the organoleptic properties of the food are reported by several authors. To decrease the required doses and improve the effectiveness of active coatings enriched with EOs, best options would be micro- and nano-encapsulation of active compounds. Besides, the use of combinations of different food preservation systems could represent another solution to the above-mentioned problem. As to toxicity, the ingestion of high doses of essential oils can cause serious problems. So, it is necessary to find out a balance between the effective compound dose and the risk of toxicity. It is also notable that the use of EOs remains expensive, so from an economic point of view this preservation strategy needs further improvement. Future research should focus on mechanisms by which antimicrobials can control microorganisms, food applications of the natural antimicrobial compounds, and the effectiveness of EOs, alone and in combination with other parts of plant extract, and other food-processing techniques [6] [81].

\section{Conflicts of Interest}

The authors declare no conflicts of interest regarding the publication of this paper.

\section{References}

[1] Tajkarimi, M.M., Ibrahim, S.A. and Cliver, D.O. (2010) Antimicrobial Herb and Spice Compounds in Food. Food Control, 21, 1199-1218.

https://doi.org/10.1016/j.foodcont.2010.02.003

[2] Arqués, J.L., Rodríguez, E., Nuñez, M. and Medina, M. (2008) Inactivation of Gram-Negative Pathogens in Refrigerated Milk by Reuterin in Combination with Nisin or the Lactoperoxidase System. European Food Research and Technology, 227, 77-82. https://doi.org/10.1007/s00217-007-0695-8

[3] Demirci, F., Guven, K., Demirci, B., Dadandi, M.Y. and Baser, K.H.C. (2008) Antibacterial Activity of Two Phlomis Essential Oils against Food Pathogens. Food Control, 19, 1159-1164. https://doi.org/10.1016/j.foodcont.2008.01.001

[4] Gutiérrez-del-Río, I., Fernández, J. and Lombó, F. (2018) Plant Nutraceuticals as Antimicrobial Agents in Food Preservation: Terpenoids, Polyphenols and Thiols. International Journal of Antimicrobial Agents, 12, 102-118.

[5] Bukvički, D., Stojković, D., Soković, M., Vannini, L., Montanari, C., Pejin, B., Savić, A., Veljić, M., Grujić, S. and Marin, P.D. (2014) Satureja horvatii Essential Oil: In Vitro Antimicrobial and Antiradical Properties and in Situ Control of Listeria monocytogenes in Pork Meat. Meat Science, 96, 1355-1360. https://doi.org/10.1016/j.meatsci.2013.11.024

[6] Del Nobile, M.A., Lucera, A., Costa, C. and Conte, A. (2012) Food Applications of 
Natural Antimicrobial Compounds. Frontiers in Microbiology, 3, 287.

[7] Davidson, P.M., Taylor, T.M. and Schmidt, S.E. (2013) Chemical Preservatives and Natural Antimicrobial Compounds. In: Doyle, M. and Beuchat, L., Eds., Food Microbiology. Fundamentals and Frontiers, 3rd Edition, ASM Press, Washington DC, 765-801.

[8] Kuorwel, K.K., Cran, M.J., Sonneveld, K., Miltz, J. and Bigger, S.W. (2011) Essential Oils and Their Principal Constituents as Antimicrobial Agents for Synthetic Packaging Films. Journal of Food Science, 76, R164-R177. https://doi.org/10.1111/j.1750-3841.2011.02384.x

[9] Garcia-Fuentes, A.R., Wirtz, S., Vos, E. and Verhagen, H. (2015) Short Review of Sulphites as Food Additives. European Journal of Nutritional Food Safety, 5, 113-120. https://doi.org/10.9734/EJNFS/2015/11557

[10] Hanušová, K., Dobiáš, J. and Klaudisová, K. (2009) Effect of Packaging Films Releasing Antimicrobial Agents on Stability of Food Products. Czech Journal of Food Science, 27, 347-349. https://doi.org/10.17221/958-CJFS

[11] Gutierrez, J., Barry-Ryan, C. and Bourke, P. (2008) The Antimicrobial Efficacy of Plant Essential Oil Combinations and Interactions with Food Ingredients. International Journal of Food Microbiology, 124, 91-97. https://doi.org/10.1016/j.ijfoodmicro.2008.02.028

[12] Embuscado, M.E. (2015) Spices and Herbs: Natural Sources of Antioxidants-A Mini Review. Journal of Functional Foods, 18, 811-819.

https://doi.org/10.1016/j.jff.2015.03.005

[13] Ahmad, V., Khan, M.S., Jamal, Q.M.S., Alzohairy, M.A., Al Karaawi, M.A. and Siddiqui, M.U. (2017) Antimicrobial Potential of Bacteriocins: in Therapy, Agriculture and Food Preservation. International Journal of Antimicrobial Agents, 49, 1-11. https://doi.org/10.1016/j.ijantimicag.2016.08.016

[14] Rose, N.L., Sporns, P. and McMullen, L.M. (1999) Detection of Bacteriocins by Matrix-Assisted Laser Desorption/Ionization Time-of-Flight Mass Spectrometry. Applied and Environmental Microbiology, 65, 2238-2242.

[15] Pateiro, M., Barba, F.J., Domínguez, R., Sant'Ana, A.S., Khaneghah, A.M., Gavahian, M., Gómez, B. and Lorenzo, J.M. (2018) Essential Oils as Natural Additives to Prevent Oxidation Reactions in Meat and Meat Products: A Review. Food Research International, 113, 156-166. https://doi.org/10.1016/j.foodres.2018.07.014

[16] Fernandes, R.P.P., Trindade, M.A., Lorenzo, J.M. and de Melo, M.P. (2018) Assessment of the Stability of Sheep Sausages with the Addition of Different Concentrations of Origanum vulgare Extract during Storage. Meat Science, 137, 244-257. https://doi.org/10.1016/j.meatsci.2017.11.018

[17] Gutierrez, J., Barry-Ryan, C. and Bourke, P. (2009) Antimicrobial Activity of Plant Essential Oils using Food Model Media: Efficacy, Synergistic Potential and Interactions with Food Components. Food Microbiology, 26, 142-150. https://doi.org/10.1016/j.fm.2008.10.008

[18] Raybaudi-Massilia, R.M., Mosqueda-Melgar, J., Sobrino-López, A., Soliva-Fortuny, R. and Martín-Belloso, O. (2009) Use of Malic Acid and Other Quality Stabilizing Compounds to Assure the Safety of Fresh-Cut "Fuji" Apples by Inactivation of Listeria monocytogenes, Salmonella enteritidis and Escherichia coli O157: H7. Journal of Food Safety, 29, 236-252. https://doi.org/10.1111/j.1745-4565.2009.00153.x

[19] Calo, J.R., Crandall, P.G., O’Bryan, C.A. and Ricke, S.C. (2015) Essential Oils as Antimicrobials in Food Systems-A Review. Food Control, 54, 111-119.

https://doi.org/10.1016/j.foodcont.2014.12.040 
[20] Bakhtiary, F., Sayevand, H.R., Khaneghah, A.M., Haslberger, A.G. and Hosseini, H. (2018) Antibacterial Efficacy of Essential Oils and Sodium Nitrite in Vacuum Processed Beef Fillet. Applied Food Biotechnology, 5, 1-10.

[21] Hyldgaard, M., Mygind, T. and Meyer, R.L. (2012) Essential Oils in Food Preservation: Mode of Action, Synergies, and Interactions with Food Matrix Components. Frontiers in Microbiology, 3, 12. https://doi.org/10.3389/fmicb.2012.00012

[22] Hashemi, S.M.B., Khaneghah, A.M., Koubaa, M., Barba, F.J., Abedi, E., Niakousari, M. and Tavakoli, J. (2018) Extraction of Essential Oil from Aloysia citriodora Palau Leaves using Continuous and Pulsed Ultrasound: Kinetics, Antioxidant Activity and Antimicrobial Properties. Process Biochemistry, 65, 197-204. https://doi.org/10.1016/j.procbio.2017.10.020

[23] Jayasena, D.D. and Jo, C. (2014) Potential Application of Essential Oils as Natural Antioxidants in Meat and Meat Products: A Review. Food Reviews International, 30, 71-90. https://doi.org/10.1080/87559129.2013.853776

[24] Tavakolpour, Y., Moosavi-Nasab, M., Niakousari, M., Haghighi-Manesh, S., Hashemi, S.M.B. and Mousavi Khaneghah, A. (2017) Comparison of Four Extraction Methods for Essential Oil from Thymus daenensis Subsp. Lancifolius and Chemical Analysis of Extracted Essential Oil. Journal of Food Processing and Preservation, 41, e13046. https://doi.org/10.1111/jfpp.13046

[25] Tongnuanchan, P. and Benjakul, S. (2014) Essential Oils: Extraction, Bioactivities, and Their Uses for Food Preservation. Journal of Food Science, 79, R1231-R1249. https://doi.org/10.1111/1750-3841.12492

[26] Gavahian, M., Farhoosh, R., Javidnia, K., Shahidi, F. and Farahnaky, A. (2015) Effect of Applied Voltage and Frequency on Extraction Parameters and Extracted Essential Oils from Mentha piperita by Ohmic Assisted Hydrodistillation. Innovative Food Science \& Emerging Technologies, 29, 161-169. https://doi.org/10.1016/j.ifset.2015.02.003

[27] Asl, R.M.Z., Niakousari, M., Gahruie, H.H., Saharkhiz, M.J. and Khaneghah, A.M. (2018) Study of Two-Stage Ohmic Hydro-Extraction of Essential Oil from Artemisia aucheri Boiss.: Antioxidant and Antimicrobial Characteristics. Food Research International, 107, 462-469. https://doi.org/10.1016/j.foodres.2018.02.059

[28] Babu, K.G.D. and Kaul, V.K. (2005) Variation in Essential Oil Composition of Rose-Scented Geranium (Pelargonium sp.) Distilled by Different Distillation Techniques. Flavour and Fragrance Journal, 20, 222-231. https://doi.org/10.1002/ffj.1414

[29] Stratakos, A.C. and Koidis, A. (2016) Methods for Extracting Essential Oils. In: Essential Oils in Food Preservation, Flavor and Safety, Academic Press, Cambridge, 31-38. https://doi.org/10.1016/B978-0-12-416641-7.00004-3

[30] Gavahian, M., Farahnaky, A., Farhoosh, R., Javidnia, K. and Shahidi, F. (2015) Extraction of Essential Oils from Mentha piperita using Advanced Techniques: Microwave Versus Ohmic Assisted Hydrodistillation. Food and Bioproducts Processing, 94, 50-58. https://doi.org/10.1016/j.fbp.2015.01.003

[31] Hashemi, S.M.B., Nikmaram, N., Esteghlal, S., Khaneghah, A.M., Niakousari, M., Barba, F.J., Roohinejad, S. and Koubaa, M. (2017) Efficiency of Ohmic Assisted Hydrodistillation for the Extraction of Essential Oil from Oregano (Origanum vulgare subsp. viride) Spices. Innovative Food Science \& Emerging Technologies, 41, 172-178. https://doi.org/10.1016/j.ifset.2017.03.003

[32] Hashemi, S.M.B., Khaneghah, A.M. and Akbarirad, H. (2016) The Effects of Amplitudes Ultrasound-Assisted Solvent Extraction and Pretreatment Time on the Yield and Quality of Pistacia khinjuk Hull Oil. Journal of Oleo Science, 65, 733-738. 
https://doi.org/10.5650/jos.ess15252

[33] Gavahian, M., Farahnaky, A. and Sastry, S. (2016) Ohmic-Assisted Hydrodistillation: A Novel Method for Ethanol Distillation. Food and Bioproducts Processing, 98, 44-49. https://doi.org/10.1016/j.fbp.2015.11.003

[34] Gavahian, M., Farahnaky, A., Shavezipur, M. and Sastry, S. (2016) Ethanol Concentration of Fermented Broth by Ohmic-Assisted Hydrodistillation. Innovative Food Science \& Emerging Technologies, 35, 45-51. https://doi.org/10.1016/j.ifset.2016.04.001

[35] Vian, M.A., Fernandez, X., Visinoni, F. and Chemat, F. (2008) Microwave Hydrodiffusion and Gravity, a New Technique for Extraction of Essential Oils. Journal Chromatography A, 1190, 14-17. https://doi.org/10.1016/j.chroma.2008.02.086

[36] Toma, M., Vinatoru, M., Paniwnyk, L. and Mason, T.J. (2001) Investigation of the Effects of Ultrasound on Vegetal Tissues during Solvent Extraction. Ultrasonics Sonochemistry, 8, 137-142. https://doi.org/10.1016/S1350-4177(00)00033-X

[37] Chemat, F., Vian, M.A. and Cravotto, G. (2012) Green Extraction of Natural Products: Concept and Principles. International Journal of Molecular Sciences, 13, 8615-8627. https://doi.org/10.3390/ijms13078615

[38] Koubaa, M., Barba, F.J., Mhemdi, H., Grimi, N., Koubaa, W. and Vorobiev, E. (2015) Gas Assisted Mechanical Expression (GAME) as a Promising Technology for Oil and Phenolic Compound Recovery from Tiger Nuts. Innovative Food Science \& Emerging Technologies, 32, 172-180. https://doi.org/10.1016/j.ifset.2015.09.019

[39] Sharif, K.M., Rahman, M.M., Azmir, J., Mohamed, A., Jahurul, M.H.A., Sahena, F. and Zaidul, I.S.M. (2014) Experimental Design of Supercritical Fluid Extraction-A Review. Journal of Food Engineering, 124, 105-116. https://doi.org/10.1016/j.jfoodeng.2013.10.003

[40] Gupta, A., Naraniwal, M. and Kothari, V. (2012) Modern Extraction Methods for Preparation of Bioactive Plant Extracts. International Journal of Applied and Natural Sciences, 1, 8-26.

[41] Chemat, F., Abert-Vian, M. and Fernandez, X. (2012) Microwave-Assisted Extraction of Essential Oils and Aromas. In: Microwave-Assisted Extraction for Bioactive Compounds, Springer, Boston, 53-68. https://doi.org/10.1007/978-1-4614-4830-3_3

[42] Li, Y., Fabiano-Tixier, A.S., Vian, M.A. and Chemat, F. (2013) Solvent-Free Microwave Extraction of Bioactive Compounds Provides a Tool for Green Analytical Chemistry. Trends in Analytical Chemistry, 47, 1-11. https://doi.org/10.1016/j.trac.2013.02.007

[43] Flamini, G., Tebano, M., Cioni, P.L., Ceccarini, L., Ricci, A.S. and Longo, I. (2007) Comparison between the Conventional Method of Extraction of Essential Oil of Laurus nobilis L. and a Novel Method which Uses Microwaves Applied in Situ, without Resorting to an Oven. Journal of Chromatography A, 1143, 36-40. https://doi.org/10.1016/j.chroma.2007.01.031

[44] Roselló-Soto, E., Galanakis, C.M., Brnčić, M., Orlien, V., Trujillo, F.J., Mawson, R., Knoerzer, K., Tiwari, B.K. and Barba, F.J. (2015) Clean Recovery of Antioxidant Compounds from Plant Foods, By-Products and Algae Assisted by Ultrasounds Processing. Modeling Approaches to Optimize Processing Conditions. Trends in Food Science \& Technology, 42, 134-149. https://doi.org/10.1016/j.tifs.2015.01.002

[45] Vilkhu, K., Mawson, R., Simons, L. and Bates, D. (2008) Applications and Opportunities for Ultrasound Assisted Extraction in the Food Industry, a Review. Innovative Food Science \& Emerging Technologies, 9, 161-169.

https://doi.org/10.1016/j.ifset.2007.04.014 
[46] Srinivasan, K. (2014) Antioxidant Potential of Spices and Their Active Constituents. Critical Reviews in Food Science and Nutrition, 54, 352-372. https://doi.org/10.1080/10408398.2011.585525

[47] Li, M., Muthaiyan, A., O’Bryan, C.A., Gustafson, J.E., Li, Y., Crandall, P.G. and Ricke, S.C. (2011) Use of Natural Antimicrobials from a Food Safety Perspective for Control of Staphylococcus Aureus. Current Pharmaceutical Biotechnology, 12, 1240-1254. https://doi.org/10.2174/138920111796117283

[48] Yang, S.C., Lin, C.H., Sung, C.T. and Fang, J.Y. (2014) Antibacterial Activities of Bacteriocins: Application in Foods and Pharmaceuticals. Frontiers in Microbiology, $5,241$.

[49] Ghrairi, T., Chaftar, N. and Hani, K. (2012) Bacteriocins: Recent Advances and Opportunities. Chapter 23, Progress in Food Preservation, 485-511. https://doi.org/10.1002/9781119962045.ch23

[50] Todorov, S.D., Franco, B.D.G.M. and Wiid, I.J. (2014) In Vitro Study of Beneficial Properties and Safety of Lactic Acid Bacteria Isolated from Portuguese Fermented Meat Products. Beneficial Microbes, 5, 351-366. https://doi.org/10.3920/BM2013.0030

[51] Chahad, O.B., El Bour, M., Calo-Mata, P., Boudabous, A. and Barros-Velàzquez, J. (2012) Discovery of Novel Bio-Preservation Agents with Inhibitory Effects on Growth of Food-Borne Pathogens and Their Application to Seafood Products. Research in Microbiology, 163, 44-54. https://doi.org/10.1016/j.resmic.2011.08.005

[52] Settanni, L. and Corsetti, A. (2008) Application of Bacteriocins in Vegetable Food Biopreservation. International Journal of Food Microbiology, 121, 123-138. https://doi.org/10.1016/j.ijfoodmicro.2007.09.001

[53] Mugochi, T., Nandakumar, M.P., Zvauya, R. and Mattiasson, B. (2001) Bioassay for the Rapid Detection of Bacteriocins in Fermentation Broth. Biotechnology Letters, 23, 1243-1247. https://doi.org/10.1023/A:1010533627292

[54] Bajpai, V.K., Baek, K.H. and Kang, S.C. (2012) Control of Salmonella in Foods by Using Essential Oils: A Review. Food Research International, 45, 722-734. https://doi.org/10.1016/j.foodres.2011.04.052

[55] Gould, G.W. (1996) Industry Perspectives on the Use of Natural Antimicrobials and Inhibitors for Food Applications. Journal of Food Protection, 59, 82-86. https://doi.org/10.4315/0362-028X-59.13.82

[56] Carraminana, J.J., Rota, C., Burillo, J. and Herrera, A. (2008) Antibacterial Efficiency of Spanish Satureja montana Essential Oil against Listeria monocytogenes among Natural Flora in Minced Pork. Journal of Food Protection, 71, 502-508. https://doi.org/10.4315/0362-028X-71.3.502

[57] Fernandes, R.P.P., Trindade, M.A., Tonin, F.G., Pugine, S.M.P., Lima, C.G., Lorenzo, J.M. and De Melo, M.P. (2017) Evaluation of Oxidative Stability of Lamb Burger with Origanum vulgare Extract. Food Chemistry, 233, 101-109. https://doi.org/10.1016/j.foodchem.2017.04.100

[58] Zhang, H., Kong, B., Xiong, Y.L. and Sun, X. (2009) Antimicrobial Activities of Spice Extracts against Pathogenic and Spoilage Bacteria in Modified Atmosphere Packaged Fresh Pork and Vacuum Packaged Ham Slices Stored at 4 C. Meat Science, 81, 686-692. https://doi.org/10.1016/j.meatsci.2008.11.011

[59] Colak, H., Hampikyan, H., Bingol, E.B. and Aksu, H. (2008) The Effect of Nisin and Bovine Lactoferrin on the Microbiological Quality of Turkish-Style Meatball (tekirdağ köfte). Journal of Food Safety, 28, 355-375. 
https://doi.org/10.1111/j.1745-4565.2008.00105.x

[60] Karabagias, I., Badeka, A. and Kontominas, M.G. (2011) Shelf life Extension of Lamb Meat using Thyme or Oregano Essential Oils and Modified Atmosphere Packaging. Meat Science, 88, 109-116. https://doi.org/10.1016/j.meatsci.2010.12.010

[61] Erkan, N., Tosun, Ş.Y., Ulusoy, Ş. and Üretener, G. (2011) The Use of Thyme and Laurel Essential Oil Treatments to Extend the Shelf Life of Bluefish (Pomatomus saltatrix) during Storage in Ice. Journal für Verbraucherschutz und Lebensmittelsicherheit, 6, 39-48. https://doi.org/10.1007/s00003-010-0587-x

[62] Goulas, A.E. and Kontominas, M.G. (2007) Combined Effect of Light Salting, Modified Atmosphere Packaging and Oregano Essential Oil on the Shelf-Life of Sea Bream (Sparus aurata): Biochemical and Sensory Attributes. Food Chemistry, 100, 287-296. https://doi.org/10.1016/j.foodchem.2005.09.045

[63] Corbo, M.R., Speranza, B., Filippone, A., Granatiero, S., Conte, A., Sinigaglia, M. and Del Nobile, M.A. (2008) Study on the Synergic Effect of Natural Compounds on the Microbial Quality Decay of Packed Fish Hamburger. International Journal of Food Microbiology, 127, 261-267. https://doi.org/10.1016/j.ijfoodmicro.2008.07.014

[64] Abou-Taleb, M. and Kawai, Y. (2008) Shelf Life of Semifried Tuna Slices Coated with Essential Oil Compounds after Treatment with Anodic Electrolyzed $\mathrm{NaCl}$ Solution. Journal of Food Protection, 71, 770-774. https://doi.org/10.4315/0362-028X-71.4.770

[65] Andevari, G.T. and Rezaei, M. (2011) Effect of Gelatin Coating Incorporated with Cinnamon Oil on the Quality of Fresh Rainbow Trout in Cold Storage. International Journal of Food Science \& Technology, 46, 2305-2311. https://doi.org/10.1111/j.1365-2621.2011.02750.x

[66] Shirazinejad, A.R., Noryati, I., Rosma, A. and Darah, I. (2010) Inhibitory Effect of Lactic Acid and Nisin on Bacterial Spoilage of Chilled Shrimp. World Academy of Science, Engineering and Technology, 41, 163-167.

[67] Bico, S.L.S., Raposo, M.F.J., Morais, R.M.S.C. and Morais, A.M.M.B. (2009) Combined Effects of Chemical Dip and/or Carrageenan Coating and/or Controlled Atmosphere on Quality of Fresh-Cut Banana. Food Control, 20, 508-514. https://doi.org/10.1016/j.foodcont.2008.07.017

[68] Ayala-Zavala, J.F., Oms-Oliu, G., Odriozola-Serrano, I., González-Aguilar, G.A., Álvarez-Parrilla, E. and Martín-Belloso, O. (2008) Bio-Preservation of Fresh-Cut Tomatoes using Natural Antimicrobials. European Food Research and Technology, 226, 1047-1055. https://doi.org/10.1007/s00217-007-0630-Z

[69] Bevilacqua, A., Corbo, M.R. and Sinigaglia, M. (2010) Combining Eugenol and Cinnamaldehyde to Control the Growth of Alicyclobacillus acidoterrestris. Food Control, 21, 172-177. https://doi.org/10.1016/j.foodcont.2009.05.002

[70] Belletti, N., Lanciotti, R., Patrignani, F. and Gardini, F. (2008) Antimicrobial Efficacy of Citron Essential Oil on Spoilage and Pathogenic Microorganisms in Fruit-Based Salads. Journal of Food Science, 73, M331-M338. https://doi.org/10.1111/j.1750-3841.2008.00866.x

[71] Tserennadmid, R., Takó, M., Galgóczy, L., Papp, T., Pesti, M., Vágvölgyi, C., Almássy, K. and Krisch, J. (2011) Anti-Yeast Activities of Some Essential Oils in Growth Medium, Fruit Juices and Milk. International Journal of Food Microbiolo$g y$, 144, 480-486. https://doi.org/10.1016/j.ijfoodmicro.2010.11.004

[72] Del Nobile, M.A., Corbo, M.R., Speranza, B., Sinigaglia, M., Conte, A. and Caroprese, M. (2009) Combined Effect of MAP and Active Compounds on Fresh Blue Fish Burger. International Journal of Food Microbiology, 135, 281-287. 
https://doi.org/10.1016/j.ijfoodmicro.2009.07.024

[73] Burt, S. (2004). Essential Oils: Their Antimicrobial Properties and Potential Applications in Foods. International Journal Food Microbiology, 94, 223-253. https://doi.org/10.1016/j.ijfoodmicro.2004.03.022

[74] Sinigaglia, M., Bevilacqua, A., Corbo, M.R., Pati, S. and Del Nobile, M.A. (2008) Use of Active Compounds for Prolonging the Shelf Life of Mozzarella Cheese. International Dairy Journal, 18, 624-630. https://doi.org/10.1016/j.idairyj.2007.11.022

[75] Ture, H., Eroglu, E., Ozen, B. and Soyer, F. (2011) Effect of Biopolymers Containing Natamycin against Aspergillus niger and Penicillium roquefortii on Fresh Kashar Cheese. International Journal of Food Science \& Technology, 46, 154-160. https://doi.org/10.1111/j.1365-2621.2010.02465.x

[76] Pinto, M.S., de Carvalho, A.F., dos Santos Pires, A.C., Souza, A.A.C., da Silva, P.H.F., Sobral, D., de Paula, J.C.J. and de Lima Santos, A. (2011) The Effects of Nisin on Staphylococcus aureus Count and the Physicochemical Properties of Traditional Minas Serro Cheese. International Dairy Journal, 21, 90-96. https://doi.org/10.1016/j.idairyj.2010.08.001

[77] Dos Santos Pires, A.C., de Fátima Ferreira Soares, N., De Andrade, N.J., Da Silva, L.H.M., Camilloto, G.P. and Bernardes, P.C. (2008) Development and Evaluation of Active Packaging for Sliced Mozzarella Preservation. Packaging Technology and Science: An International Journal, 21, 375-383. https://doi.org/10.1002/pts.815

[78] Al-Otaibi, M. and Demerdash, H.E. (2008) Improvement of the Quality and Shelf Life of Concentrated Yoghurt (Labneh) by the Addition of Some Essential Oils. African Journal of Microbiology Research, 2, 156-161.

[79] Belewu, M.A., El-Imam, A.A., Adeyemi, K.D. and Oladunjoye, S.A. (2012) Eucalyptus Oil and Lemon Grass Oil: Effect on Chemical Composition and Shelf-Life of Soft Cheese. Environment and Natural Resources Research, 2, 114. https://doi.org/10.5539/enrr.v2n1p114

[80] Fisher, K. and Phillips, C. (2008) Potential Antimicrobial Uses of Essential Oils in Food: Is Citrus the Answer? Trends in Food Science \& Technology, 19, 156-164. https://doi.org/10.1016/j.tifs.2007.11.006

[81] Turgis, M., Borsa, J., Millette, M., Salmieri, S. and Lacroix, M. (2008) Effect of Selected Plant Essential Oils or Their Constituents and Modified Atmosphere Packaging on the Radiosensitivity of Escherichia coli O157:H7 and Salmonella Typhi in Ground Beef. Journal of Food Protection, 71, 516-521. https://doi.org/10.4315/0362-028X-71.3.516 